If we start from the well-researched position that severe disturbances of emotional development are likely to be enacted in later life, and add Adshead's observation that this is often manifest in care-seeking behaviour with psychiatric services, it is a small step to propose that resources are used in some proportion to that disturbance. Conversely, disturbance of attachment can be 'weighed' like patients' case notes, by the input from the services that they receive.

So perhaps the cost-offset studies for personality disorder, such as the Henderson Hospital work (Menzies et al, 1993) are measuring improvement in dysfunctional attachment patterns as well as counting money. Clinicians in therapeutic communities and other settings for treating emotionally unstable personality disorder are likely to be more comfortable thinking that they are making a fundamental difference to the way patients relate to others, than that they are doing it to save money, but perhaps they are the same thing.

Adshead, G. (1998) Psychiatric staff as attachment figures. Understanding management problems in psychiatric services in the light of attachment theory. British Journal of Psychiatry. 172, 64-69.

Menzles, D., Dolan, B. M. \& Norton K. (1993) Are short term savings worth long term costs? Funding treatment for personality disorders. Psychiotric Bulletin. 17. 517-519.

R. Haigh Winterbourne Therapeutic Community, 53-55 Argyle Road, Reading RGI 7YL

\section{PTSD and victims of torture}

Sir: I read with interest the article by GorstUnsworth \& Goldenberg (1998) on psychiatric morbidity in Iraqi victims of torture. The authors speculate on the causes of the relatively low level of post-traumatic stress disorder (PTSD) within their sample compared with the rate found among Vietnam veterans.

While it is of interest to compare the rates of PTSD in various high-risk groups, it is important not to lose sight of the specific features of each of these groups. Torture is, by and large, a highly selective act employed by tyrannical states against certain individuals for a complex range of political purposes. It is rarely an indiscriminate act. In the Iraqi context, torture is used as a routine form of social control which is meant to terrorise the individual concerned (and/or extract information from the victim) as well as to act as a deterrent to others. The targets of the torture are carefully selected from suspected activists or other independently minded individuals who appear to stand out among their peers and who are judged to pose a short- or long-term threat.

From the point of view of the tyrannical state, torture is a finite resource (limited by the availability of 'skilled torturers') that must be deployed to best effect. The nonrandom nature of the targets of torture is in clear contrast to other victims of disaster, where either minimal or no selection applies (e.g. victims of road traffic accidents or the veterans of a conscript army).

An understanding of the interaction beween the victims' characteristics and the characteristics of the trauma may offer us a better chance of predicting the level of risk of developing a particular psychiatric syndrome following traumatic and stressful events.

\section{Gorst-Unsworth, C. Goldenbere, E. (1998)} Psychological sequence of torture and organised violence suffered by refugees from Iraq. Trauma-related factors compared with social factors in exile. British journal of Psychiatry. 172. 90-94.

R.T. Abed Department of Psychiatry, Rotherham District General Hospital, Moorgate Road,

Rotherham S60 2UD

\section{Cost-effective community psychiatry}

Sir: There is good evidence to support Dr Tyrer's (1998) point that fragmenting community care for serious mental illness leads to longer hospital admissions. In a natural unplanned experiment during the Daily Living Programme of home-based care in south-east London, removing the community care team's responsibility for any crisis admissions of their patients led to a trebling in duration of those crisis admissions (Marks et al, 1994). Having the same staff responsible for the patient's community care and any crisis admissions seemed critical if care was to remain cost-effective.

Marks, I. M., Connolly, J., Muljen, M., ot of (1994) Home-based versus hospital-based care for people with serious mental illness. British journal of Psychiatry, 165 , 179-194.

Tyrer, P. (1998) Cost-effective or profligate community psychiatry? British journal of Psychiotry, 168, I.

1. M. Marks Institute of Psychiatry, De Crespigny Park, London SE5 8 AF

\section{Sulpiride augmentation on schizophrenia}

Sir: I would like to comment on the article by Shiloh et al (1997) which suggests an augmenting effect of sulpiride in patients who failed to respond satisfactorily to clozapine.

The population studied comprised patients with schizophrenia who, after receiving clozapine for 12 weeks at daily doses ranging from 350 to $600 \mathrm{mg}$, showed a partial clinical response. Most British psychiatrists would not consider these patients as resistant to clozapine and would increase the daily dose, side-effects allowing, up to $900 \mathrm{mg}$.

Recent clinical plasma levels studies on clozapine support this practice, pointing to the importance of achieving values in excess of $370 \mathrm{ng} / \mathrm{ml}$ (Buckley, 1996). When Miller et al (1994) raised the dose in seven patients not responding to clozapine who had plasma concentrations below $370 \mathrm{ng} /$ $\mathrm{ml}$, five of them improved. It has to be added that Kane et al (1988), in their seminal study on the effectiveness of clozapine in treatment-resistant patients, prescribed daily doses of up to $900 \mathrm{mg}$.

It is therefore possible that the clinical improvement obtained in the study was not due to any specific pharmacodynamic effect, but was caused by an aspecific increase in the dopamine blockade in a population which was receiving clozapine at a subtherapeutic dosage. The same effect would probably have been achieved by adding any of the other major tranquillisers or, better still, increasing the dose of clozapine. Bone marrow depression, which is the most dangerous adverse effect of clozapine, is not dose dependent. It would, therefore, be unwise to advocate a polypharmaceutical regimen, which introduces the very unpleasant side-effects secondary to the sulpiride-induced hyperprolactinaemia, instead of just increasing the dose of clozapine.

As a last point it is unlikely that, as suggested in the article, the augmenting effect of sulpiride could be due to a pharmacokinetic interference at the level of the P450 liver metabolism of clozapine. The hepatic metabolism of sulpiride is, in fact, negligible, more than $95 \%$ of the compound being excreted unchanged in the urine (Imondi et al, 1978).

Buckdey R. F. (1996) Treatment of schizophrenia: advances during the decade of the brain. British journol of Hospital Medicine, 11. 574-580. 